\title{
An Innovative Solution for the Power Quality Problems in Induction Motor by Using Silica and Alumina Nano Fillers Mixed Enamel for the Coatings of the Windings
}

\begin{abstract}
K. Mohanadasse ${ }^{\dagger}$, C. Sharmeela* and D. Edison Selvaraj**
Abstract - Power quality has always been a concern of power engineers. Certainly an argument can be successfully made that most parts of power engineering have the ultimate objective to improve power quality. AC motors were widely used in industrial and domestic applications. Generally, AC motors were of two types: Induction and Synchronous motors. In motor many parameters like different load cycling, switching, working in hot weather and unbalances creates harmonics which creates major reasons for temperature rise of the motors. Due to high peak value of voltage, harmonics can weaken insulation in cables, windings and capacitors and different electronic components. Higher value of harmonics increase the motor current and decrease the power factor which will reduce the life time of the motor and increase the overall rating of all electrical equipments. Harmonics reduction of all the motors in India will save more power. Coating of windings of the motor with nano fillers will reduce the amount of harmonics in the motor. Based on the previous project works, actions were taken to use the enamel filled with various nano fillers for the coating of the windings of the different $\mathrm{AC}$ motors. Ball mill method was used to convert the micro particles of $\mathrm{Al}_{2} \mathrm{O}_{3}, \mathrm{SiO}_{2}, \mathrm{TiO}_{2}, \mathrm{ZrO}_{2}$ and $\mathrm{ZnO}$ into nano particles. SEM, TEM and XRD were used to augment the particle size of the powder. The synthesized nano powders were mixed with the enamel by using ultrasonic vibrator. Then the enamel mixed with the nano fillers was coated to the windings of the several AC motors. Harmonics were measured in terms of various indices like THD, VHD, CHD and DIN by using Harmonic analyzer. There are many other measures and indices to describe power quality, but none is applicable in all cases and in many instances, these indices may hide more than they show. Sometimes power quality indices were used as a basis of comparison and standardization. The efficiency of the motors was increased by $5-10 \%$. The thermal withstanding capacity of the motor was increased by $5^{\circ}$ to $15^{\circ} \mathrm{C}$. The harmonics of the motors were reduced by $10-50 \%$.
\end{abstract}

Keywords: Single phase induction motor, Enamel, Coating, Nano filler, Load test, $\mathrm{SiO}_{2}, \mathrm{Al}_{2} \mathrm{O}_{3}$

\section{Introduction}

In recent years, a great deal of attention has been given to the applications of nano fillers in the field of electrical insulating materials. It has been examined that the use of nano fillers to the enamel used in the motors can greatly improve the thermal, mechanical and electrical properties of it $[1,3]$. The efficiency of the induction motor depends upon the properties of the enamel used for the coating of the windings of the motor [2]. For single phase induction motors, the enamel was used for three purposes: impregnation, coating and adhesion. The efficiency of the single phase induction motor could be increased by adding the nano fillers with the enamel which was used as coating

$\dagger$ Corresponding Author: Dept. of Electrical and Electronics Engineering, St. Joseph's College of Engineering, Chennai, India. (electrical-researchkmd@gmail.com)

* Dept. of Electrical and Electronics Engineering, A.C. Tech., Anna University, Chennai, India. (sharmeela20@yahoo.com)

** Dept. of Electrical and Electronics Engineering, Panimalar Engineering College, Chennai, India. (edisonsivakasi@gmail.com)

Received: September 28, 2014; Accepted: January 29, 2015 for the windings of the motor. In this paper, the efficiency of the normal single phase induction motor, $\mathrm{SiO}_{2}$ nano filler mixed enamel coated single phase induction motor and $\mathrm{Al}_{2} \mathrm{O}_{3}$ was analyzed and the results were compared with each other [8]. Heat run test was performed on the single phase induction motors to determine the total loss of energy dissipated as heat [4]. It was well-known that the operating temperature of the motor has a very strong relationship with the life duration of the insulation. The enamel used for coating of the machine windings were organic in nature and were adversely affected by thermal decomposition. Harmonics create a major problem in the field of power system. Due to high peak value of voltage, harmonics can weaken insulation in cables, windings and capacitors and different electronic components. Higher value of harmonics increase the motor current and decrease the power factor which will reduce the life time of the motor and increase the overall rating of all electrical equipments. Harmonics reduction of all the motors in India will save more power. Coating of windings of the motor with nano fillers will reduce the amount of harmonics in 
the motor. Harmonics will cause the following problems:

(1). Reduction of efficiency of the motor

(2). Ageing of the electrical components

(3). Malfunctioning and failure of electronic equipment

(4). Overheating and failure of electric motors

(5). Excessive measurement errors

(6). Electromagnetic interference

(7). Spurious operation of protective devices.

\section{Coating of the Nano Filler Added Enamel to the Windings of the Motor}

Ball mill method was used to prepare the nano powders of $\mathrm{SiO}_{2}$ and $\mathrm{Al}_{2} \mathrm{O}_{3}$. SEM was used to augment the particle size of $\mathrm{SiO}_{2}$ and $\mathrm{Al}_{2} \mathrm{O}_{3}$ [5]. Figs. 1 and 2 shows the SEM images of $\mathrm{SiO}_{2}$ and $\mathrm{Al}_{2} \mathrm{O}_{3}$ before ball mill process.

\subsection{Figures}

Figs. 3 and 4 shows the SEM images of $\mathrm{SiO}_{2}$ after ball mill process. The sizes of the particles are in the range from 40 to $100 \mathrm{~nm}$ size.

$5 \mathrm{wt} \%$ of nano powder of $\mathrm{SiO}_{2}$ and $\mathrm{Al}_{2} \mathrm{O}_{3}$ was taken and it was mixed with the enamel by using ultrasonic vibrator. Then this enamel was coated on the windings of the single phase induction motor. The specifications of the single phase induction motor were shown in the Table 1.

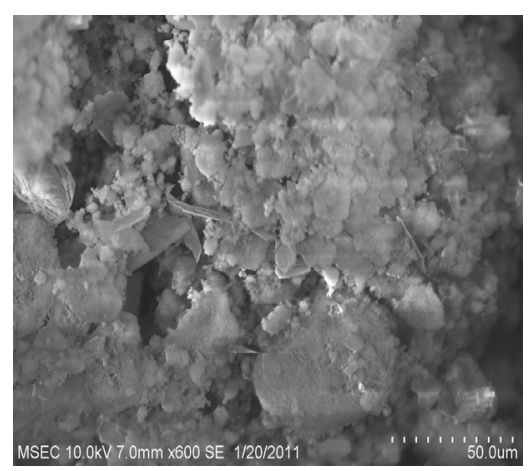

Fig. 1. SEM analysis of $\mathrm{SiO}_{2}$ at $50 \mu \mathrm{m}$

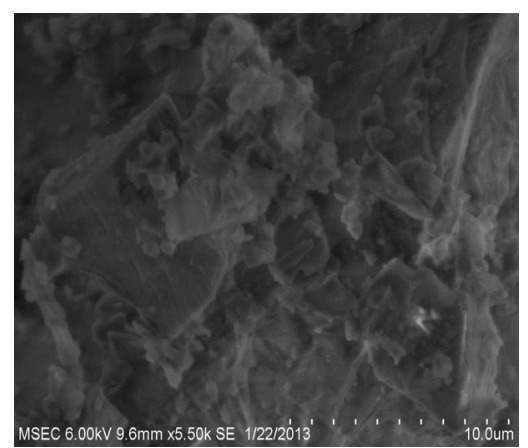

Fig. 2. SEM analysis of $\mathrm{Al}_{2} \mathrm{O}_{3}$ at $50 \mu \mathrm{m}$

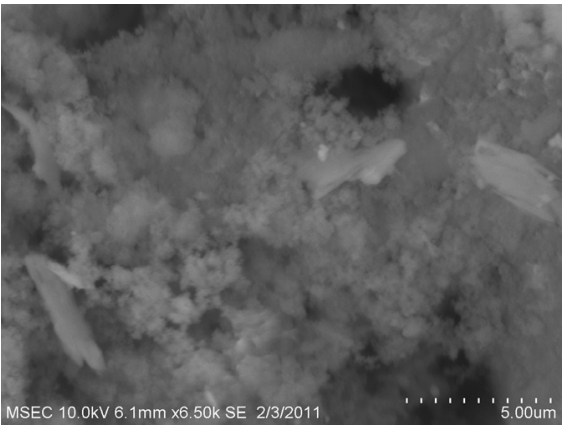

Fig. 3. SEM analysis of $\mathrm{SiO}_{2}$ at $50 \mathrm{~nm}$

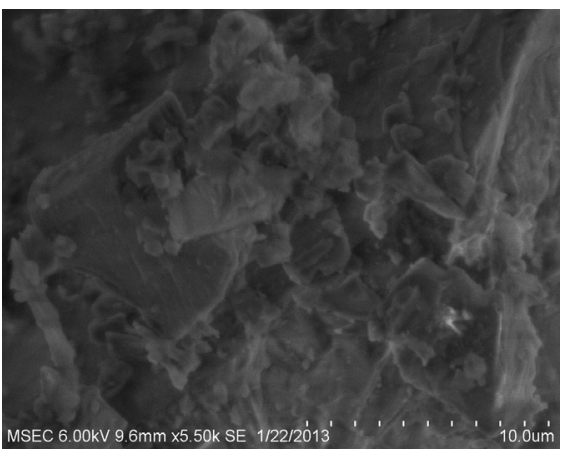

Fig. 4. SEM analysis of $\mathrm{Al}_{2} \mathrm{O}_{3}$ at $50 \mathrm{~nm}$

Table 1. Specifications of the Single phase induction motor

\begin{tabular}{c|c}
\hline Quantity & Rating \\
\hline Power & $0.5 \mathrm{HP}$ \\
\hline Speed & $1500 \mathrm{rpm}$ \\
\hline Current & $4 \mathrm{~A}$ \\
\hline Voltage & $220 \mathrm{~V}$ \\
\hline
\end{tabular}

\section{Experimental Analysis}

\subsection{Load test}

The load test was done as per the circuit diagram and arrangement shown in the Figs. 5 and 6. The maximum efficiency obtained from an ordinary induction motor was $69 \%$. The maximum efficiency obtained from $\mathrm{SiO}_{2}$ nano filler mixed enamel coated induction motor was $74 \%$. The maximum efficiency obtained from $\mathrm{Al}_{2} \mathrm{O}_{3}$ nano filler mixed enamel coated induction motor was $75 \% . \quad \mathrm{Al}_{2} \mathrm{O}_{3}$ nano fillers have excellent electrical, thermal, mechanical and physical properties. $\mathrm{SiO}_{2}$ nano fillers have high level of resistance to partial discharge, high purity, large surface area, good thermal, electrical and mechanical properties. One of the reasons for the increase in efficiency of the motor by adding nano fillers was mainly due to the reduction in the dielectric losses and harmonic losses.

The output power, current, efficiency, and speed were measured on the ordinary and nano coated single phase induction motor. The readings were shown in the Table 2 to 4 . 


\subsection{Tables}

Table 2. Experimental values of V, I, P, N, T and $\eta$ for the normal single phase induction motor

\begin{tabular}{c|c|c|c|c|c|c|c|c|c}
\hline S.No. & Line voltage in (V) & Line current (A) & Input power $(\mathrm{W})$ & Speed $(\mathrm{rpm})$ & $\mathrm{F}_{1}(\mathrm{~kg})$ & $\mathrm{F}_{2}(\mathrm{~kg})$ & Torque $(\mathrm{Nm})$ & Output power (W) & Efficiency $(\%)$ \\
\hline 1 & 219.5 & 3.9 & 380 & 1475 & 1.4 & 4 & 1.02 & 157.58 & 41.46 \\
\hline 2 & 219.5 & 4 & 412 & 1470 & 1.5 & 5 & 1.37 & 211.41 & 51.31 \\
\hline 3 & 219.5 & 4.2 & 492 & 1460 & 1.6 & 7.3 & 2.23 & 341.96 & 69.50 \\
\hline 4 & 219.5 & 4.3 & 520 & 1460 & 1.6 & 7.6 & 2.35 & 359.96 & 69.22 \\
\hline 5 & 219.5 & 4.4 & 548 & 1455 & 1.7 & 8 & 2.47 & 376.67 & 68.73 \\
\hline
\end{tabular}

Table 3. Experimental values of V, I, P, N, T and $\eta$ for $\mathrm{SiO}_{2}$ nano coated single phase induction motor

\begin{tabular}{c|c|c|c|c|c|c|c|c|c|c}
\hline S.No. & Line voltage in (V) & Line current (A) & Input power $(\mathrm{W})$ & Speed (rpm) & $\mathrm{F}_{1}(\mathrm{~kg})$ & $\mathrm{F}_{2}(\mathrm{~kg})$ & Torque (Nm) & Output power (W) & Efficiency (\%) \\
\hline 1 & 220 & 4 & 365 & 1480 & 5 & 2 & 1.172 & 181.55 \\
\hline 2 & 220 & 4.1 & 410 & 1478 & 7 & 3 & 1.56 & 224.32 & 58.7 \\
\hline 3 & 219.5 & 4.2 & 445 & 1470 & 9 & 3.5 & 2.15 & 330.79 & 74.33 \\
\hline 4 & 219.5 & 4.3 & 510 & 1465 & 10 & 3.8 & 2.43 & 372.60 & 73.05 \\
\hline 5 & 219 & 4.4 & 570 & 1450 & 11 & 3.9 & 2.78 & 421.91 \\
\hline
\end{tabular}

Table 4. Experimental values of V, I, P, N, T and $\eta$ for $\mathrm{Al}_{2} \mathrm{O}_{3}$ nano coated single phase induction motor

\begin{tabular}{c|c|c|c|c|c|c|c|c|c}
\hline S.No. & Line voltage in (V) & Line current (A) & Input power $(\mathrm{W})$ & Speed (rpm) & $\mathrm{F}_{1}(\mathrm{~kg})$ & $\mathrm{F}_{2}(\mathrm{~kg})$ & Torque (Nm) & Output power (W) & Efficiency (\%) \\
\hline 1 & 220 & 4 & 340 & 1480 & 6 & 3 & 1.1772 & 182.44 \\
\hline 2 & 220 & 4.1 & 400 & 1475 & 7.3 & 3 & 1.6873 & 26.42 \\
\hline 3 & 220 & 4.2 & 444 & 1465 & 8 & 3 & 1.9620 & 300.99 & 65.15 \\
\hline 4 & 220 & 4.3 & 464 & 1460 & 8 & 2.4 & 2.1974 & 335.96 & 72.40 \\
\hline 5 & 220 & 4.3 & 520 & 1450 & 9 & 2.5 & 2.5506 & 387.29 \\
\hline
\end{tabular}

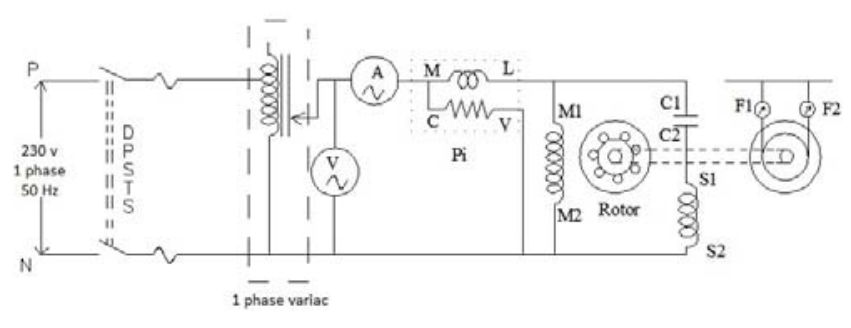

Fig. 5. circiut diagram

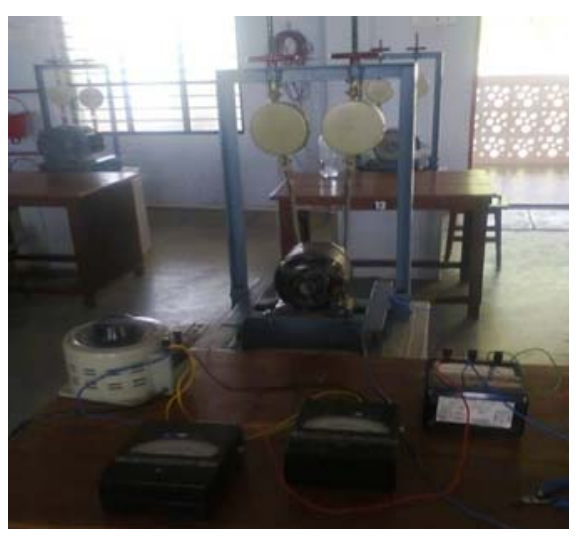

Fig. 6. circuit arrangement

\subsection{Temperature test}

Heat run test was done on electric machines to determine the total loss of energy dissipated as heat [6, 7]. It was well-known that the operating temperature of an electric machine has a very strong relationship with the life duration of the insulation. Heat run test was conducted on the single phase induction motor as per IEC 60851. The temperature of the motor was measured under different conditions and the readings were shown in the Table 5. The life time of the motor was dependent on the losses of the motor. When the losses were reduced, the heat rise in the motor will also be reduced. Generally, the energy due to losses was dissipated in the form of heat energy. The thermal withstanding capacity was increased due to the reduction in dielectric and harmonic losses present in the motor.

Table 5. Measurement of temperature on the windings of the single phase induction motor

\begin{tabular}{c|c|c|c}
\hline $\begin{array}{c}\text { Time } \\
(\text { min })\end{array}$ & $\begin{array}{c}\text { Normal } \\
\text { single phase } \\
\text { induction } \\
\text { motor }\left({ }^{\circ} \mathrm{C}\right)\end{array}$ & $\begin{array}{c}\mathrm{SiO}_{2} \text { nano filler mixed } \\
\text { enamel coated single } \\
\text { phase induction motor } \\
\left({ }^{\circ} \mathrm{C}\right)\end{array}$ & $\begin{array}{c}\mathrm{Al}_{2} \mathrm{O}_{3} \text { nano filler } \\
\text { mixed enamel coated } \\
\text { ingle phase induction } \\
\text { motor }\left({ }^{\circ} \mathrm{C}\right)\end{array}$ \\
\hline 0 & 30 & 30 & 30 \\
\hline 5 & 44 & 40 & 40 \\
\hline 10 & 48 & 43 & 43 \\
\hline 15 & 50 & 47 & 46 \\
\hline 20 & 53 & 49 & 49 \\
\hline 25 & 55 & 51 & 50 \\
\hline 30 & 57 & 54 & 53 \\
\hline
\end{tabular}

\subsection{Measurement of harmonics}

The total harmonic distortion was a measurement of the harmonic distortion present and was defined as the ratio of 
the sum of the powers of all harmonic components to the power of the fundamental frequency. THD was used to characterize the linearity of audio systems and the power quality of electric power systems. In power systems, lower THD means reduction in peak currents, heating, emissions, and core loss in motors. Total harmonic distortion was measured as the percentage. Lower percentages were better. In reality, total harmonic distortion was hardly perceptible to the human ear. Voltage distortion consists of very sharp notches and spikes in voltage. When applied to the equivalent circuit, that high frequency voltage does not cause much change in the inductive magnetizing current, but causes a change in the load current. Current THD was caused by the motor itself due to non-linearity of the magnetizing current. The current THD will be higher when the motor was unloaded. The THD was the means to express the distortion affecting a current or voltage flowing at a given point as a single number. THD analysis was done according to the standard IEC $61000-2-2$. The harmonics of the motors were reduced by $10-50 \%$. Fig. 7 shows the comparison of VHD for motors with and without nano coating.
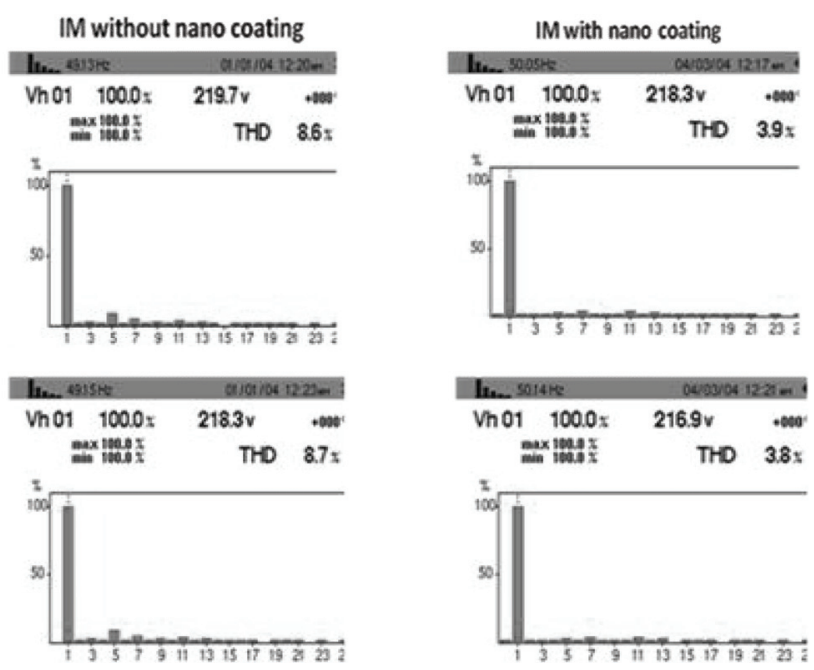

Fig. 7. Comparison of VHD for motors with and without nano coating

\section{Conclusions}

The following observations were clear as per this research:

1. The efficiency of the induction motor was increased by $5 \%$ by adding nano filler of $\mathrm{SiO}_{2}$ to the enamel used as the coating for the windings of the single phase induction motor. The efficiency of the induction motor was increased by $6 \%$ by adding nano filler of $\mathrm{Al}_{2} \mathrm{O}_{3}$ to the enamel used as the coating for the windings of the single phase induction motor. The increase in efficiency of the motor by adding nano fillers was mainly due to the reduction in the dielectric losses and harmonic losses.

2. The addition of $\mathrm{SiO}_{2}$ nano fillers to the enamel has also improved the temperature withstanding capacity of the induction motor by $5.26 \%$. The addition of $\mathrm{Al}_{2} \mathrm{O}_{3}$ nano fillers to the enamel has also improved the temperature withstanding capacity of the induction motor by $7 \%$. The thermal withstanding capacity of the motor was increased due to the reduction in dielectric and harmonic losses present in the motor. Hence the life time of the motor will be increased.

3. The harmonics of the motors were reduced by $10-$ $50 \%$.

\section{References}

[1] H. Oraee, "A Quantitative Approach to Estimate the Life Expectancy of Electric Motors", IEEE Transaction on Dielectrics and Electrical Insulation, Vol. 7, No. 6, Dec. 2000, pp. 790-796.

[2] K. Inuzuka, H. Inano, N. Hayakawa, T. Hirose, M. Hamaguchi, and H. Okubo, "Partial discharge characteristics of nanocomposite enameled wire for inverter fed motor," 2006 Annu. Rep. Conf. Elect. Insul. Dielect. Phenomena, Kansas City, 2006, pp. 594-597.

[3] Guoqin Zhang, Guangning Wu, Laisheng Tong, Enguang, "Study of Nano TiO2 Filler in the Corona resistant Magnetic Wire Insulation Performance of Inverter-fed Motor", Proceedings of international Symposium on Electrical Insulating Materials, June 5-9, 2005, Kitakyushu, Japan A3-8, 2005.

[4] Selvaraj, D. Edison. "Characterization of dielectric properties of the enamel filled with carbon nanotubes for the frequency range of $50 \mathrm{~Hz}-5 \mathrm{MHz}$." International Journal of Science and Engineering Applications 1.2 (2012): 102-106.

[5] Selvaraj, D. Edison, and C. Pugazhendhi Sugumaran. "Comparative Analysis of Dielectric Properties of Enamel Filled with Various Nanofillers such as $\mathrm{ZrO}_{2}$, $\mathrm{Al}_{2} \mathrm{O}_{3}, \mathrm{CNT}$ and $\mathrm{ZnO}$." International Journal of Science and Engineering Applications 1.1 (2012): 5155.

[6] Selvaraj, D. Edison. "Partial discharge characteristics of enamel filled with micro and nano composite of $\mathrm{SiO}_{2}$ and $\mathrm{TiO}_{2}$." International Journal of Science and Engineering Applications 1.2 (2012): 95-101.

[7] Selvaraj D. Edison, et al. "Analysis of Efficiency, Thermal Withstanding Capacity and Electromagnetic Interference of Three Phase Squirrel Cage Induction Motor Coated with $\mathrm{SiO}_{2} \& \mathrm{TiO}_{2}$ Nano Composite Filled Enamel." International Journal of Science and Engineering Applications 1.1 (2012): 17-21.

[8] Edison Selvaraj. D, C. Pugazhendhi Sugumaran, and A. SivaPrakash, "Characterization of Electrical and Thermal Properties of Enamel Filled with Carbon 
Nanotubes," Proceedings of the Third International Conference on Trends in Information, Telecommunication and Computing, Springer New York, 2013.

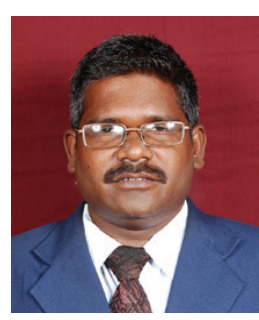

K.Mohanadasse He holds a B.Tech. in Electrical and Electronics Engineering from Pondicherry University, M.E. in Power Systems Engineering from Annamalai University and a Ph.D. Scholar in Electrical Engineering in Anna University, Chennai, India. At present, he holds the post of Associate Professor in EEE, St. Joseph's College of Engineering, Chennai -600 119. His research areas of interest include power quality, power electronics applications to power systems.

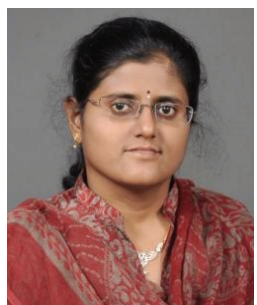

C. Sharmeela He holds a B.E. in Electrical and Electronics Engineering, M.E. in Power Systems Engineering from Annamalai University and a $\mathrm{PhD}$ in Electrical Engineering from Anna University. At present, she holds the post of Assistant Professor (Senior Grade.) in EEE, A. C. Tech., Anna University, Chennai. She has done a number of consultancies for Power quality measurements and design of compensators for industries. Her areas of interest include Power Quality, Power Electronics applications to Power Systems and Renewable Energy Systems. She is a Lifemember of the Institution of Engineers (India), ISTE and SSI.

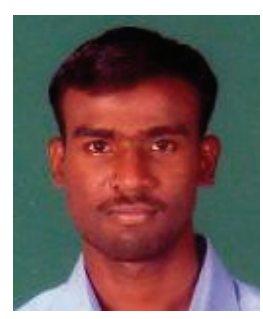

D. Edison Selvaraj He was born in Sivakasi on $13^{\text {th }}$ November 1985 to Mr. S. David Nadar and D. Elizabeth Rani. He belongs to Christian Nadar Community. He was a member in Ragland Memorial Church, Sivakasi. He carried out his early schooling in Seventh Day Adventist Matriculation School, Sivakasi and AVM Marimuthu Nadar Higher Secondary School, Vilampatti. He received the B.E. degree in Electrical and Electronics Engineering from Sree Sowdambika College of Engineering affiliated to Anna University, Chennai in 2007 and M.E. degree in High-Voltage Engineering from Anna University, Chennai, Tamilnadu, India in 2010. He obtained Sixteenth Rank in B.E. degree and First Rank in M.E. degree. He has 5 years of teaching experience in various Engineering Colleges. He has published 150 papers in various International Journals, Conferences and Symposiums. He has attended various
Workshops, Seminars, FDP, Short term courses and training programs. He was a technical committee member for many international conferences. He was Guest Editor and Lead Editor for many international journals. He received Shiksha Rattan Puraskar Award from IIFS, New Delhi. His name was also nominated for various awards. His biography was recognized in Marquis Who's Who, Asia / Pacific Who's Who and International Biographical Center. He was appointed as technical paper reviewer for various International Journals. He was doing research in the Applications of Nano technology in Electrical Engineering. His area of interest was Nano Dielectrics, Nano Motors, Nano Transformers, Nano Capacitors and Nano Electrical Apparatuses. He was the member of various Professional bodies like IEEE, ISTE, ACEEE, IAENG, IACSIT, UACEE, IDES, IETE and SCIEI. Presently, he was working as Assistant Professor in the Department of Electrical and Electronics Engineering, Panimalar Engineering College, Chennai, India and Guest Faculty in the Department of Electrical and Electronics Engineering, College of Engineering, Guindy, Anna University, Chennai, India. 